\title{
多峰性最適問題の一解法
}

\author{
久保洋 \\ 北海道大学工学部 札幌市北区北 13 条西 8 丁目 \\ (昭和 47 年 2 月 2 日 受付)
}

\section{A Method for Solving Multimodal Optimization Problems}

\author{
Hiroshi Kuво \\ (Faculty of Engineering, Hokkaido University, Sapporo) \\ (Received February 2, 1972)
}

At present, there are a few methods of multimodal optimization technique, which are used in order to find a solution case by case. The global search techniques which are used in all of these methods are usually nonsequential ones. In this paper, we make an attempt at using only a sequential technique in this global search.

As is commonly known, a necessary condition for the differentiable scalar function to become optimal is that its first derivative is equal to zero. When the function is defined over on $n$-dimensional space, the first derivatives generate hypersurfaces. A point which is any intersection of $n$ hypersurfaces of derivatives is defined as a pole. The intersection of $n-1$ hypersurfaces, taking off any one from these $n$ hypersurfaces, forms a curve, which is defined as a pole line. A curve evidently links a pole with another. The principle of the method proposed in this paper is to search sequentially these poles using the network of these pole lines. The existence and uniqueness of the pole line, the relation between the pole line and the pole, and the selecting of a resolution from poles are proved.

This method needs that the performance measure is of the class $\mathrm{C} 2$ because of the existence of continuous hypersurfaces, and furthermore that some unequality constraints are of the class $\mathrm{C} 1$ and close the feasible domain because of closing the network of pole lines. Otherwise, it may occur that an optimal solution is not found in this method, for all of extremums found in this method are connected with a certain network of pole lines. In particular, it is impossible to find the solution which exists on the boundary of unequality constraints, but in this case the method finding it using Lagrange multiplier is briefly described. Furthermore, the convergence of solutions in this method under certain conditions and two simple experimentations are reported.

\section{1. ま え がき}

より複雑かつ高度な問題などで最適化を目指す場合, 単峰性が仮定できない場合が非常に多く存在する。し かしながら多峰性最適問題の解法は，まだまだ未開拓 の分野で応用に即したじゃっかんの手法が提案されて いるにすぎない(1) 3)。またと机らはランダム法，タブ レーション法などの非逐次的な大局的探索で解の近傍 を求め, さらに単峰性の仮定のもとに従来のシーケン

$†$ 第 10 回計測自動制御学会学術講演会で発表 (昭 46.8)
シャル法を使って精度をあげる場合が普通である．本 論文は極值と極值を結ぶ曲線を導入することにより， この大局的探索にも逐次的な手法のみを使うことを試 みたものである.

一般にn次元ベクトル空間で定義される可微分なス カラー関数の極值の条件は，それぞれ超曲面を生成す るn個の 1 階偏導関数がゼ口等しいことで示される. この条件を満たすこれら $n$ 個の超曲面の交点を極と定 義し， 1 個除いた $(n-1)$ 個の交わりを極を通る曲線 となることから極值線と定義する，明らかなように， 
この極值線は極と極を結ぶ性質をもっている．本論文 で提案する方法は, この極值線の存在, 極值線と極と の関係，特よび極が極值であるかどらかの条件学導く ことによりこの極值線をネットワーク状に追跡しな がら，極値を逐次探索してゆく方法である.

本手法で怯，この極值線のネットワークを閉じたも のにするために閉じた不等式拘束が必要であり，また 連続な極值線が存在するために目的関数の 2 階偏導関 数之不等式拘束の 1 階偏導関数の存在が必要である. また求まる解は㟧る極值線でつながった極值の中での 最適解であるが，一般には最適解が得られると思われ る、以下必要な定理の証明とアルゴリズム，さらにあ る条件のもとで本手法が収束することを示し，簡単な 2つの例題についての実験例も報告する。

\section{2. 理 論 解 析}

一般に最適問題は次の形をしている。ここに $\boldsymbol{X}$ は $n$ 次元ベクトルであり（3）式で記す.

【問題の記述】（1）式の目的関数を（2）式の拘 束条件を満足しながら最大あるい㵊小にする点 $\boldsymbol{X}^{*}$ を求めょ.

$$
\begin{array}{cl}
\max \text { or } \min & f(\boldsymbol{X}) \\
\text { subject to } p_{i}(\boldsymbol{X}) \geq 0 \quad(i=1,2, \cdots, m) \\
\boldsymbol{X}=\left(x_{1}, x_{2}, \cdots, x_{n}\right)^{t} \quad(t: \text { 転置 })
\end{array}
$$

次㳊 $f(\boldsymbol{X}), p_{i}(\boldsymbol{X})$ 飞連続性の仮定と, $\boldsymbol{X}$ の存在の 仮定をする。

【仮定`1】 $f(\boldsymbol{X})$ は 2 階導関数, $p_{\imath}(\boldsymbol{X})$ は 1 階導 関数が存在する. 以下の議論のためこれらの導関数を 次のよ5に記す。.

$$
\begin{gathered}
\boldsymbol{g}(\boldsymbol{X})=\left(g_{1}(\boldsymbol{X}), g_{2}(\boldsymbol{X}), \cdots, g_{n}(\boldsymbol{X})\right)^{t} \\
\left(g_{i}(\boldsymbol{X})=\partial f(\boldsymbol{X}) / \partial x_{i}\right) \\
\boldsymbol{H}(\boldsymbol{X})=\left(\boldsymbol{h}_{1}(\boldsymbol{X}), \boldsymbol{h}_{2}(\boldsymbol{X}), \cdots, \boldsymbol{h}_{n}((\boldsymbol{X}))^{t}\right. \\
\left(\boldsymbol{h}_{i}(\boldsymbol{X})=\partial g_{i}(\boldsymbol{X}) / \partial \boldsymbol{X}\right) \\
\boldsymbol{b}_{i}(\boldsymbol{X})=\partial p_{i}(\boldsymbol{X}) / \partial \boldsymbol{X} \quad(i=1,2, \cdots, m)
\end{gathered}
$$

【仮定 2】拘束条件によるX $\boldsymbol{X}$ の存在可能領域が存 在し，連結した閉領域である.

拘束のない場合, 極值の必要条件は $\boldsymbol{g}\left(\boldsymbol{X}^{*}\right)=0$ で 示される. これは $n$ 個の連立方程式の解ともい党るが， 幾何学的には $n$ 個の超曲面の交点とも解釈できる. こ のとき $\boldsymbol{h}_{i}\left(\boldsymbol{X}^{*}\right)$ 注超曲面 $g_{i}\left(\boldsymbol{X}^{*}\right)=0$ の点 $\boldsymbol{X}^{*}$ での 法線ベクトルとなっている。，同様飞 $p_{i}(\boldsymbol{X})=0$ も超 曲面を生成し， $\boldsymbol{b}_{i}(\boldsymbol{X})$ はこの面の法線ベクトルとな っている. この超曲面の交点を拘束のある場合にも拡 張して次のように極を定義する。また自由度を 1 つ除 いた $(n-1)$ 個の超曲面の交わりは曲線となり，これ を極值線と定義する。
【定義 1】（4）と（5）式の $(n+m)$ 個の超曲面 の任意の $n$ 個の交点を極と定義する.

$$
\begin{array}{ll}
g_{i}(\boldsymbol{X})=0 & (i=1,2, \cdots, n) \\
p_{j}(\boldsymbol{X})=0 & (j=1,2, \cdots, m)
\end{array}
$$

【定義 2】（4）之（5）式の $(n+m)$ 個の超曲面 の任意の $(n-1)$ 個の交線を極值線と定義する。市る 点 $\boldsymbol{X}^{0}$ で $(n-1)$ 個の $g_{i}\left(\boldsymbol{X}^{0}\right)=0$ あるいは $p_{j}\left(\boldsymbol{X}^{0}\right)$ $=0$ を满足しているとする。 このときと机らの超曲面 の法線ベクトル $\boldsymbol{h}_{i}\left(\boldsymbol{X}^{0}\right)$ あるいは $\boldsymbol{b}_{j}\left(\boldsymbol{X}^{0}\right)$ を列之す る $n \times(n-1)$ マトリクス $\bar{G}\left(\boldsymbol{X}^{0}\right)$ を導入する.

【定理 1】(極值線の一意性) 極值線上の任意の 点 $\boldsymbol{X}^{0}$ でマトリクス $\overline{\boldsymbol{G}}\left(\boldsymbol{X}^{0}\right)$ のランクが $(n-1)$ なら ば，極值線の接ベクトル $\boldsymbol{V}\left(\boldsymbol{X}^{0}\right)$ はとの近傍で一意偟 定まる。

【証明】点 $\boldsymbol{X}^{0}$ が $(n-1)$ 個の $q_{i}\left(\boldsymbol{X}^{0}\right)=0$ を満 たしているとする. $\overline{\boldsymbol{G}}\left(\boldsymbol{X}^{0}\right)$ のランクが $(n-1)$ なので これらの法線ベクトル $\boldsymbol{r}_{i}\left(\boldsymbol{X}^{0}\right)$ は互いに独立である. また $\boldsymbol{V}\left(\boldsymbol{X}^{0}\right)$ は（6）式を満足する。したがって $\boldsymbol{V}$ $\left(\boldsymbol{X}^{0}\right)$ は自由度が 1 となり一意性がい光る。(証明終)

$$
\boldsymbol{V}\left(\boldsymbol{X}^{0}\right)^{t} \cdot \boldsymbol{r}_{i}\left(\boldsymbol{X}^{0}\right)=0 \quad\left(i: q_{i}\left(\boldsymbol{X}^{0}\right)=0\right)
$$

定理 1 により $\overline{\boldsymbol{G}}\left(\boldsymbol{X}^{0}\right)$ のランクが $(n-1)$ ならば極 值線は分枝しないことが保障される。李たとのランク が $(n-1)$ より小さい $k$ とすると， $\boldsymbol{V}\left(\boldsymbol{X}^{0}\right)$ は $(n-k)$ 次元を張るが，このとさはその近傍で空間内に $(n-k)$ 個の点をとり極值線の分枝を調べる必要がある.

【定義 3】極值線上で $\overline{\boldsymbol{G}}\left(\boldsymbol{X}^{0}\right)$ のランクが $(n-1)$ より小さくなり極值線が分枝する点を，分枝点と定義 する。

任意の極点 $\boldsymbol{X}^{*}$ で满足している $n$ 個の関数 $q_{\imath}\left(\boldsymbol{X}^{*}\right)$ $=0$ の法線ベクトル $\boldsymbol{r}_{i}\left(\boldsymbol{X}^{*}\right)$ を列とする $n \times n$ マトリ クス $\overline{\boldsymbol{H}}\left(\boldsymbol{X}^{*}\right)$ を導入する.

【定理 2】（極と極値線の関係） $\boldsymbol{X}^{*}$ を任意の極 とする. $\overline{\boldsymbol{H}}\left(\boldsymbol{X}^{*}\right)$ のランクが $n, p_{i}\left(\boldsymbol{X}^{*}\right)=0$ を満足し ている個数を $c$ とすると, その極から出ている極值線

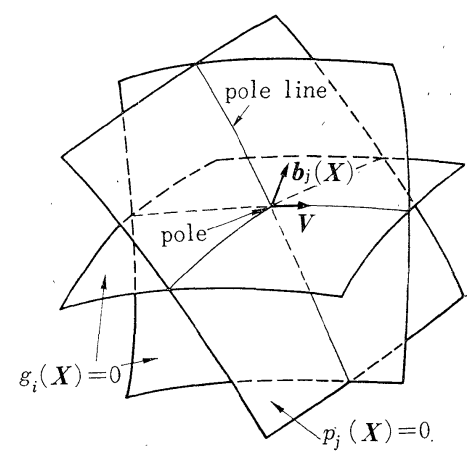

Fig. 1 Relation of pole and pole line 
方向ベクトル $\boldsymbol{V}\left(\boldsymbol{X}^{*}\right)$ の個数は $(7)$ 式で示される.

【証明】 $\boldsymbol{X}^{*}$ が満足している関数のらち $q_{j}\left(\boldsymbol{X}^{*}\right)$ $=0$ を 1 個除くと, 残りの法線ベクトルから作られる マトリクス $\overline{\boldsymbol{G}}\left(\boldsymbol{X}^{*}\right)$ のランクは $(n-1)$ となり, 定理 1 から $\boldsymbol{X}^{*}$ の近傍での極値線方向ベクトル $\boldsymbol{V}_{j}\left(\boldsymbol{X}^{*}\right)$, 一 $\boldsymbol{V}_{j}\left(\boldsymbol{X}^{*}\right)$ が一意に 2 個求をる. $q_{j}\left(\boldsymbol{X}^{*}\right)$ が $g_{j}\left(\boldsymbol{X}^{*}\right)$ のときはこれらは $c$ 個の $p_{j}\left(\boldsymbol{X}^{*}\right)=0$ の超曲面上のべ クトルとなり，いずれも拘束を満足する. $q_{i}\left(\boldsymbol{X}^{*}\right)$ が $p_{i}\left(\boldsymbol{X}^{*}\right)$ のときはいずれか一方が $p_{i}\left(\boldsymbol{X}^{*}\right) \geq 0$ を満足 しない，したがって極值線方向ベクトルの個数は (7) 式となる。

(証明終)

$$
2(n-c)+c=2 n-c
$$

定理 2 からマトリクス $\overline{\boldsymbol{H}}\left(\boldsymbol{X}^{*}\right)$ のランクが $れ$ のき は極 $X^{*}$ より出る極值線方向ベクトルとその個数が 求まる。 $\overline{\boldsymbol{H}}\left(\boldsymbol{X}^{*}\right)$ のランクが $n$ より小さいkのときは, $\boldsymbol{X}^{*}$ の近傍の $(n-k)$ 次元空間内に $(n-k)$ 個の点を とり極值線方向ベクトルとその個数を調ベる必要があ る。

次に極の特性に関する定理を証明して稀く．定理 2 之同じく極 $\boldsymbol{X}^{*}$ が $c$ 個の拘束 $p_{i}\left(\boldsymbol{X}^{*}\right)=0$ を満足し, $\overline{\boldsymbol{H}}\left(\boldsymbol{X}^{*}\right)$ のランクはnとする。このとき $\boldsymbol{b}_{i}\left(\boldsymbol{X}^{*}\right)$ は $c$ 次元部分空間 $L を$ 張る。この空間内に互いに直交する $c$ 個の単位ベクトル $e_{1} \sim e_{c}$ を作る。むた $L$ の直交補 空間 $M$ の内にも $(n-c)$ 個の互いに直交する単位心 クトル $e_{c+1} \sim e_{n}$ を作る. これら $\boldsymbol{e}_{j}$ を行とする $n \times n$ マトリクスUを導入する。このUはユニタリ行列とな り，変換後も内積とノルムは保存される. また $(n-c)$ 次元空間 $M$ は拘束 $p_{i}\left(\boldsymbol{X}^{*}\right)=0$ の交わりの空間にな っている.

【定理 3】(極の特性) 定理 2 と同じく極 $X^{*}$ は $c$ 個の $p_{i}\left(\boldsymbol{X}^{*}\right)=0$ を満足し， $\overline{\boldsymbol{H}}\left(\boldsymbol{X}^{*}\right)$ のランクは $n$ とする。極 $X^{*}$ は（8）式のベクトルの第1から第 $c$ 要素までが0であり，かつ（9）式のマトリクスの 第 1 ～第 $c$ 行，第 1 列〜第 $c$ 列を除いた $(n-c) \times(n$ -c）マトリクスが正定值かつ（10）式がすべて正な らば極小值, 負定值かつ負ならば極大值, その他は不 定の極となる。

$$
\begin{gathered}
\boldsymbol{U}^{t} \cdot \boldsymbol{g}\left(\boldsymbol{X}^{*}\right) \\
\boldsymbol{U}^{t} \cdot \boldsymbol{H}\left(\boldsymbol{X}^{*}\right) \cdot \boldsymbol{U} \\
\boldsymbol{g}\left(\boldsymbol{X}^{*}\right)^{t} \cdot \boldsymbol{b}_{i}\left(\boldsymbol{X}^{*}\right) \quad\left(i: p_{i}\left(\boldsymbol{X}^{*}\right)=0\right)
\end{gathered}
$$

【証明】(11) 式は $f(\boldsymbol{X})$ の点 $\boldsymbol{X}^{*}$ での 2 階まで の展開をUを使って変換したものである.第 1 項は $M$ 空間では仮定により0である.したがって $M$ 空間内に 特ける極の判定は, 直交座標系 $\boldsymbol{U} \cdot d \boldsymbol{X}$ を持つへシア ンマトリクス（9）式を使ってできる．またL空間内 ではこう配 $\boldsymbol{g}\left(\boldsymbol{X}^{*}\right)$ と $d \boldsymbol{X}$ の存在可能方向ベクトル
$\boldsymbol{b}\left(\boldsymbol{X}^{*}\right)$ の内積で判定できる

（証明終）

$$
\begin{gathered}
f\left(\boldsymbol{X}^{*}+d \boldsymbol{X}\right)-f\left(\boldsymbol{X}^{*}\right)=\left(\boldsymbol{U} \cdot \boldsymbol{g}\left(\boldsymbol{X}^{*}\right)\right)^{t} \cdot(\boldsymbol{U} \cdot d \boldsymbol{X}) \\
+\frac{1}{2}(\boldsymbol{U} \cdot d \boldsymbol{X})^{t} \cdot\left(\boldsymbol{U}^{t} \cdot \boldsymbol{H}\left(\boldsymbol{X}^{*}\right) \cdot \boldsymbol{U}\right) \cdot(\boldsymbol{U} \cdot d \boldsymbol{X})
\end{gathered}
$$

\section{3.アルゴリズム}

以上の極と極值線の関係を使ってアルゴリズムを組 立てる. まず全体のフローチャートを Fig. 2 に示す また以下に使用されるパラメータを Table 1 に示す。

【アルゴリズム 1】探索を開始する準備をし, 次 の各ステップからなる.

Table 1 Explanation of parameter

\begin{tabular}{l|l}
\hline HM, AL, IP & input parameter \\
$S X(n)$ & searching point \\
$P X(n)$ & record of pole \\
$S V(n)$ & searching vector \\
$P V(n)$ & record of pole line vector \\
SR & radius of searching hypersphere \\
PR & record of radius of pole \\
NP & record of number of vector \\
$\mathrm{IPX}$ & record of pole charactaristic \\
$E X(n)$ & dummy point \\
\hline
\end{tabular}

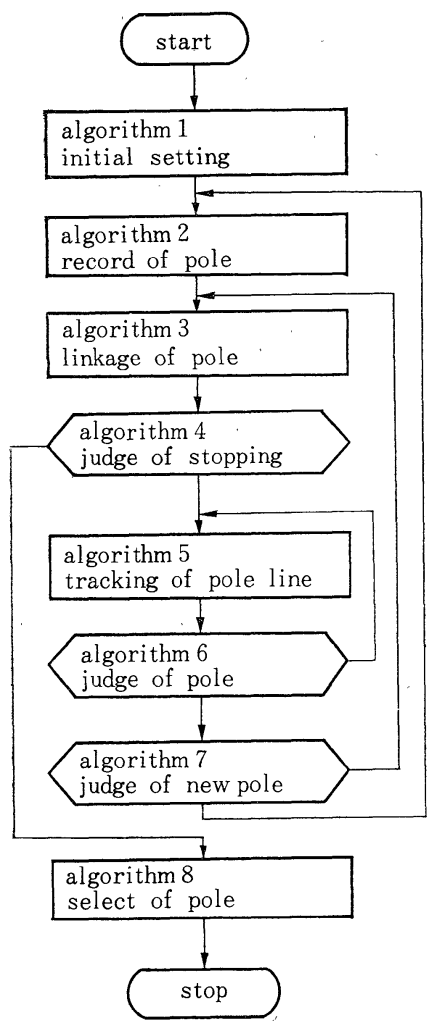

Fig. 2 System flow-chart 
i ) HM, AL, IP と探索開始座標 $S X(n)$ の読み込 Zx.

ii）最初の極 1 個の探索. これは探索ステップ $S V$ （n）が大きいときは（12）式によるグラジェント法, 小さくなると（13）式によるニュートン法を使う．こ こで $\boldsymbol{H}$ は拘束にかかっている $c$ 個の $p_{i}=0$ の法線べ クトル $\boldsymbol{b}_{i}$ を行に, 残りの $(n-c)$ 個は $g_{j}$ のらちで 小さいものの $\boldsymbol{h}_{j}$ を行にする。また $\boldsymbol{B}$ はそれに対応 する $p_{i}$ と $g_{j}$ である.

iii）極 $S X(n)$ の近傍で単峰を保障する超球の半径: $S R$ を(14) 式で計算する.

$$
\begin{gathered}
S V(n)=-\sum \frac{p_{i}}{H M} \times \frac{\boldsymbol{b}_{i}}{\left\|\boldsymbol{b}_{i}\right\|}-\sum \frac{g_{j}}{H M} \times \frac{\boldsymbol{h}_{j}}{\left\|\boldsymbol{h}_{j}\right\|} \\
S V(n)=\boldsymbol{H}^{-1} \cdot \boldsymbol{B} \\
S R=\min \left\{\left|\frac{\operatorname{det} \boldsymbol{H}}{n \cdot A L \cdot H M^{n-1}}\right|,\left|\frac{p_{i}}{H M}\right|,\left|\frac{g_{j}}{H M}\right|\right\}
\end{gathered}
$$

【アルゴリズム 2】(Fig. 3) ‘極と極值線のネッ トワークを作るためのパラメータを登録する。

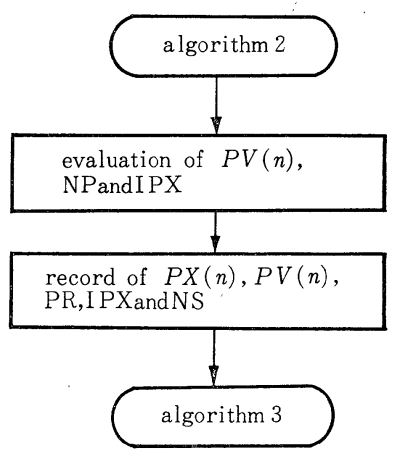

Fig. 3 Flow-chart for algorithm 2

i ) 極の座標 $S X(n)$ を $P X(n)$ そ, $\mathrm{SR}$ を $\mathrm{PR}$ に 登録.

ii）定理 2 により極值線探索方向の単位ベクトルと その個数を $P V(n)$ とP に登録.

iii）定理 3 による極の特性を計算し IPX に登録.

【アルゴリズム 3】極值線探索を開始した探索方 向ベクトルと, 到達した極の極值線探索方向ベクトル の中で同じ極值線になるものをリンケージする．この 到達した極の探索方向べクトルは探索しないので，探 索する極值線探索方向べクトルは全体の半分となる.

【アルゴリズム4】登録された探索方向ベクトル の中でまだリンケージされないものを順番に探索して ゆく.

i ）すべての探索方向がリンケージされると探索を 終了しアルゴリズム 8 へ, 残っていると,

ii）次の極值線探索方向ベクトル $P V(n)$ を $S V(n)$

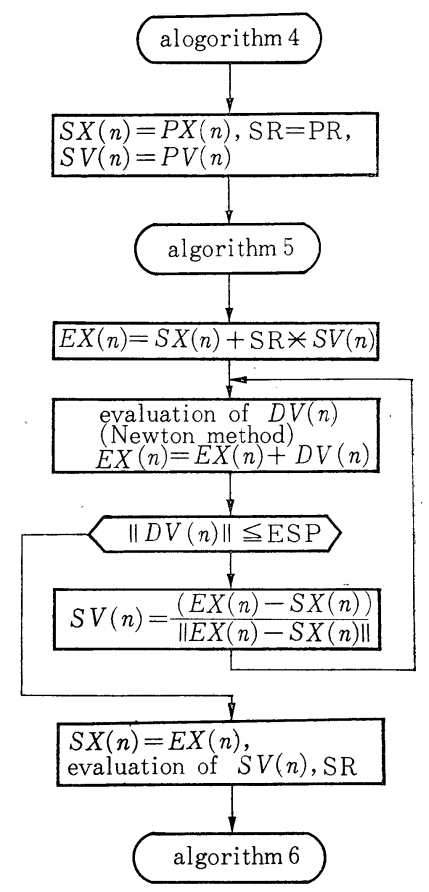

Fig. 4 . Flow-chart for algorithm 5

とし，その極の座標 $P X(n)$ を $S X(n), \mathrm{PR}$ を $\mathrm{SR}$ してアルゴリズム 5 へゆく.

【アルゴリズム 5】（Fig. 4) 極值線探索に特け る次の極值線上の点として, $S X(n)$ を中心に半径 $S R$ の超球と極值線との交点を求め, その点を $S X(n)$ と して探索方向ベクトル $S V(n)$ と超球の半径 $S R$ を計 算する.

i ) $S X(n)$ より $S V(n)$ の方向に距離 $S R$ の点 $E X$ (n) を（15）式から求める.

ii） $E X(n)$ を通り $S V(n)$ に直交する超平面と極值 線の交点の探索. これは (13) 式によるニュートン法 を使う．ここで $\boldsymbol{H}$ は探索中の極值線の満足する（n一 1) 個の $q_{i}=0$ の法線ベクトルを $\boldsymbol{r}_{i}$ 行に, 残りの 1 行は $S V(n)$ を使う。また $\boldsymbol{B}$ は $\boldsymbol{r}_{i}$ に対応する $(n-1)$ 個は $q_{i}$, 残りは 0 とする.

iii）（17）式により $E X(n)$ を $S X(n)$ より $S R$ の 距離に修正し, その修正ステップ幅 (16) 式が判定值 より大きければ（18）式により $S V(n)$ を修正して ii) に戻る. 判定值より小さければ iv) $E X(n)$ を $S X(n)$ としこの点での探索方向べクトル $S V(n)$ を計算し,

(19）式により $S R$ を計算しアルゴリズム 6 へゆく.

$$
\begin{gathered}
E X(n)=S X(n)+S Q \times S V(n) \\
\|E X(n)-S X(n)\|-R \\
E X(n)=S X(n)+\frac{S R \times(E X(n)-S X(n))}{\|E X(n)-S X(n)\|}
\end{gathered}
$$




$$
S V(n)=\frac{E X(n)-S X(n)}{\|E X(n)-S X(n)\|}
$$

$S R=\min \left\{\left|\frac{\operatorname{det} \boldsymbol{H}}{(n-1) \cdot A L \cdot H M^{n-2}}\right|,\left|\frac{p_{j}}{H M}\right|,\left|\frac{g_{j}}{H M}\right|\right\}$ ( $q_{i}$ は除く)

【アルゴリズム 6】 アルゴリズム 5 で求めた $S X(n)$ が探索中以外の $p_{j} \geq 0$ を満足しないかあるい は $g_{j}$ の符号が変わると極を通過したことがわかる.

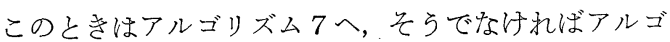
リズム 5 ヘゆく

【アルゴリズム 7】新しい極かどらかを判定する。 i ）アルゴリズム 1 と同じくニュートン法で極 $S X$ (n) の精度をある。

ii） $S X(n)$ がすでに登録済みの極 $P X(n)$ を中心 とした半径 $P R$ の超球の中にあればアルゴリズム 3 へ，そらでなければ (14) 式で $S R$ を計算しアルゴリ ズムへゆく.

【アルゴリズム 8】解とする極を打出す.このと き入力パラメータ IP を使って必要な解の条件を入れ て扰く.IP=0 のときはすべての極を打出す. IP >0 のとさは極大值を関数值の大きい順に IP 個打出す. $\mathrm{I} \mathrm{P}<0$ のときは極小值を関数值の小さい順に - IP 個 打出す．また極の判定は IPX を使う。

\section{4. 収束の証 明}

3.で述べたアルゴリズムの収束性を保障するには， 1）登録する極と極值線の個数の有限性，2）極值線の ステップ幅決定のさいに極や分枝点をとばさないこと, がいえればよい。しかし任意の関数についてはこれら を証明することは不可能である：以下，目的関数と拘 束条件が仮定 $1 ， 2$ 以外にどのような条件を満足すれ ば，アルゴリズムの収束性が保障されるかを示す。

【証明 1】極と極值線の有限性は（4）之（5） 式の超曲面の存在とその独立性がいえればよい，陰関 数の定理から $\boldsymbol{h}_{i}(\boldsymbol{X})$ と $\boldsymbol{b}_{i}(\boldsymbol{X})$ が0でなければ超曲 面は存在する。同じく面の独立性は $\boldsymbol{h}_{i}(\boldsymbol{X})$ と $\boldsymbol{b}_{i}(\boldsymbol{X})$ が互いにすべての点で異なればよい。ただしある 1 点 でこれらが 0 または一致してもその近傍で超曲面の存 在と独立性はいえる。したがって $\boldsymbol{h}_{i}(\boldsymbol{X})$ と $\boldsymbol{b}_{i}(\boldsymbol{X})$ がある領域で 0 杂たは 1 次従属にならなければ極と極 值線の個数は有限である.

【証明 2】極劣い極值線上の任意の点 $\boldsymbol{X}^{0}$ で $p_{i}\left(\boldsymbol{X}^{0}\right)=0$ あるいは $g_{i}\left(\boldsymbol{X}^{0}\right)=0$ を満足しているもの を $q_{i}\left(\boldsymbol{X}^{0}\right)=0$ とし，その法線ベクトルを $\boldsymbol{r}_{i}\left(\boldsymbol{X}^{0}\right)$ と する. その他の $p_{j}\left(\boldsymbol{X}^{0}\right), g_{j}\left(\boldsymbol{X}^{0}\right)$ を $h_{j}\left(\boldsymbol{X}^{0}\right)$ とする。 また探索ステップを $R \cdot \boldsymbol{V}(\|\boldsymbol{V}\|=1)$ とする。極をと ばさないためには（20）式を満足すればよい。これを
保障するために $h_{j}(\boldsymbol{X})$ の最大変化率として (21) 式 を仮定する，Xの存在可能領域内でこれが満足される と，(22）式を満足する $R$ については極をとばさない ことが保障される。次に分枝点をとばさないためには， $\boldsymbol{X}^{0}$ が極のときは $\boldsymbol{r}_{i}$ を行としたマトリクス $\boldsymbol{G}$ ，極值 線上のときは $(n-1)$ 個の $\boldsymbol{r}_{i}$ と $\boldsymbol{V}$ を行としたマト リクス $\bar{G}$ 導入して（23）と（24）式が満たされれば よい。このため $q_{i}$ の最大変化率を(25) 式で仮定す

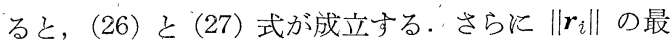
大変化率を(28) 式で仮定すれば，(26）と（27）式の 最大変化率はそれぞれ（29）と（30）式となる。乙た がって $\boldsymbol{X}$ の存在可能領域内で (25) と（28）式の仮 定が満たされると，(31) と（32）式を満たすRについ ては分枝点をとばさないことが保障される．以上のこ とから (21) と (28) 式を満足するように $H M$ と $A L$ がとられると収束が保障される。この $H M$ と $A L$ は 目的関数亡拘束条件のなめらかさを規定する1つの方 法である.

$$
h_{j}\left(\boldsymbol{X}^{0}+\alpha \times R \times \boldsymbol{V}\right) \times h_{j}\left(\boldsymbol{X}^{0}\right) \geq 0 \quad(0 \leq \alpha \leq 1)
$$

$$
\begin{gathered}
\| \frac{\partial h_{j}(\boldsymbol{X})}{\partial \boldsymbol{X}} \mid \leq H M \\
R \leq\left|\frac{h_{j}\left(\boldsymbol{X}^{0}\right)}{H M}\right|
\end{gathered}
$$

$\operatorname{det} \boldsymbol{G}\left(\boldsymbol{X}^{0}+\alpha \times R \times \boldsymbol{V}\right) \times \operatorname{det} \boldsymbol{G}\left(\boldsymbol{X}^{0}\right) \geq 0 \quad(0 \leq \alpha \leq 1)$

$$
\begin{aligned}
& \operatorname{det} \overline{\boldsymbol{G}}\left(\boldsymbol{X}^{0}+\alpha \times R \times V\right) \times \operatorname{det} \overline{\boldsymbol{G}}\left(\boldsymbol{X}^{0}\right) \geq 0 \\
& (0 \leq \alpha \leq 1) \\
& \left\|\boldsymbol{r}_{i}(\boldsymbol{X})\right\| \leq H M \\
& |\operatorname{det} \boldsymbol{G}(\boldsymbol{X})| \leq H M^{n} \\
& |\operatorname{det} \overline{\boldsymbol{G}}(\boldsymbol{X})| \leq H M^{n-1} \\
& \left\|\frac{\partial\left\|\boldsymbol{r}_{i}(\boldsymbol{X})\right\|}{\partial \boldsymbol{X}}\right\| \leq A L \\
& \left\|\frac{\partial \operatorname{det} \overline{\boldsymbol{G}}(\boldsymbol{X})}{\partial \boldsymbol{X}}\right\| \leq n \times A L \times H M^{n-1} \\
& \left\|\frac{\partial \operatorname{det} \overline{\boldsymbol{G}}(\boldsymbol{X})}{\partial \boldsymbol{X}}\right\| \leq(n-1) \times A L \times H M^{n-2} \\
& R \leq\left|\operatorname{det} \boldsymbol{G}\left(\boldsymbol{X}^{0}\right)\right| / n \times A L \times H M^{n-1} \\
& R \leq \operatorname{det} \overline{\boldsymbol{G}}\left(\boldsymbol{X}^{0}\right) \|(n-1) \times A L \times H M^{n-2}
\end{aligned}
$$

\section{5. 実験例亡考察}

プログラムはフォートランでューディングし，約 600 ステップである. 目的関数と拘束条件はサブルー チン・プログラムの形で，メイン・プログラムとつな がっている。またそれらの導関数は偏微分した関数形 でサブルーチン・プログラムに含まれている。

使用した計算機は北海道大学大形計算機センターの 
FACOM 230/60 である。以下の計算機使用時間は, コンパイラーと $I / 0$ 時間を除いたプログラム 実行時 間である。

\section{【例題 1】}

$$
\begin{array}{cll}
\text { 目的関数 } & f(\boldsymbol{X})=\sum_{i=1}^{n} 2^{1-i} \times x_{i}{ }^{2} & \\
\text { 拘束条件 } & p_{i}(\boldsymbol{X})=10-x_{i} \geq 0 & (i=1,2, \cdots, n) \\
& p_{n+i}(\boldsymbol{X})=x_{i}+8 \geqq 0 & (i=1,2, \cdots, n)
\end{array}
$$

\section{【例題 2】}

$$
\begin{array}{ll}
\text { 目的関数 } & f(\boldsymbol{X})=\sum_{i=1}^{n}\left(-\cos \frac{x_{i}}{2}\right) \\
\text { 拘束条件 } & p_{1}(\boldsymbol{X})=r^{2}-\sum_{i=1}^{n} x_{i}{ }^{2} \geqq 0
\end{array}
$$

例題はいずれも次元数 $n$ を変化できる．例題 1 は目 的関数のみでは最小值 1 個の単峰であるが, $2 n$ 個の 超立方体の拘束条件によりこれらの頂点に $2^{n}$ 個の極 大值をもつ. 例題 2 はカーブした極值線の追跡を試み るために，拘束条件として1個の超球を用いる。また この超球の半径 $っ$ 変化して, 同次元での極の個数を 変えることができる。

【結果】 Table 2 に, 例題 1 を用いてパラメー タ $H M, A L$ と次元数 $n$ を变化させた結果を示す.

Table 3 洌題 2 の次元数 $n=3$ として超球の半径 rを変化させた結果走示す、いずれもすべての極が求 まっている。

Table 2. Result of example 1

\begin{tabular}{l|r|r|r|r}
\hline experiment number & 1 & 2 & 3 & 4 \\
dimension & 3 & 3 & 4 & 5 \\
number of poles & 27 & 27 & 81 & 243 \\
number of maximum poles & 8 & 8 & 16 & 32 \\
number of minimum poles & 1 & 1 & 1 & 1 \\
number of pole line vectors & 108 & 108 & 432 & 1620 \\
HM(real value=2) & 2 & 20 & 2 & 2 \\
AL(real value=0) & $10^{-9}$ & $10^{-9}$ & $10^{-9}$ & $10^{-9}$ \\
CPU time [s] & 19 & 151 & 177 & 1924 \\
\hline
\end{tabular}

Table 3 Result of example 2

\begin{tabular}{l|r|r}
\hline experiment number & 5 & 6 \\
radius of hy persphere & 10 & 15 \\
number of poles & 73 & 183 \\
number of maximum poles & 0 & 8 \\
number of minimum poles & 7 & 7 \\
CPU time [s] & 105 & 925 \\
\hline
\end{tabular}

$$
\begin{aligned}
& \text { dimension }=3 \\
& \mathrm{HM}(\text { real })=0.25 \\
& \mathrm{AL}(\text { real })=0.125 \\
& \mathrm{HM}=0.5 \\
& \mathrm{AL}=1.0
\end{aligned}
$$

【考察】非常に簡単な例題であるが，極値線をネ
ットワーク状に探索するといら本手法の試みを実験的 に確かめた. 以下本手法の問題点などについてじゃっ かん考察を加光る。

本手法は，ある極值線につながった極值の中での最 適化を行なうという準最適化の形をとっている．最適 解が得られない場合はｉ）拘束内で他に独立した極 值線のネットワーク上に解がある場合，ii）不等式拘 束の境界面に解がある場合，の 2 つの場合が存在する。 前者については，その可能性が非常に小さいことから 一般には最適解が得られると思われる. 後者について はラグランジュ乗数を使って，境界面の等式拘束を拘 束のない問題に変換して本手法を使らことにより解を 求めることが可能である. 特にそのさい, 拘束の内側 の極值線と拘束面との交点が必ず変換後の問題に沶け る極值線上の点になり, かつラグランジュ乗数が 0 と なりなたとの逆も成立する。

また本手法では目的関数と拘束条件のなめらかさを 推定する必要がある.とくに $H M$ 注（次元数一2）乗 で効き，これらは計算時間にかなり影響する。推定が 困難な場合などには，本手法自体に適応性をもたせる こと，あるいは目的関数になんらかの平滑化を行なら ことなどが考えられる、実際的には収束性を犠牲にし て AL を非常に小さくすると計算時間を短くするこ とができる。

最後に，本手法に括汗る計算上の制限については， 次元数の増加に伴い極値線の本数と不定の極が急激に 增加し, 数時間の計算時間が可能として 5, 6 次元, 記憶容量が $40 \mathrm{~kW}$ 程度として 1000 個程度の極の探 索が限度と思われる。

\section{6. む. す. ひ}

本手法は 2 階偏導関数が利用できる場合にはかなり 有効な多峰性最適問題の解法と予想され，いち扣らの 成果は得られたと思う。とくに，同程度の極值を多数 見つける必要がある場合にも使用可能であるら。

抢わりに，日ごろご指導いただいている北海道大学 工学部沖野教郎教授に心から感謝いたします。

\section{参 考 文 献}

1) I. N. Bocharov and A.A. Fel'dbaum : An Automatic Optimizer for the Search of the smallest of $\mathrm{Sev}^{-}$ eral Minima: A \& RC, 23-3 (1962)

2) G. J. McMurtry and K. S. Fu : A Variable Structure Automaton Used as a Multimodal Searching Technique, IEEE Trans. AC, AC-11, July (1966)

3) J. D. Hill: A Search Technique for Multimodal Surfaces, IEEE Trans. SSC, SSC-5-1 (1969) 